\title{
Author Correction: Whole-genome resequencing of 472 Vitis accessions for grapevine diversity and demographic history analyses
}

\author{
Zhenchang Liang, Shengchang Duan, Jun Sheng, Shusheng Zhu, Xuemei Ni, Jianhui Shao, Chonghuai Liu, \\ Peter Nick, Fei Du, Peige Fan, Ruzhi Mao, Yifan Zhu, Weiping Deng, Min Yang, Huichuan Huang (D, Yixiang Liu, \\ Yiqing Ding, Xianju Liu, Jianfu Jiang, Youyong Zhu, Shaohua Li, Xiahong He, Wei Chen \& Yang Dong
}

Correction to: Nature Communications https://doi.org/10.1038/s41467-019-09135-8, published online 13 March 2019.

In the original version of this Article, in the last paragraph of the first section of the Results, the ratios of SNPs located in the intergenic regions, SNPs located in the coding sequences, and indels located in the coding regions are incorrectly written as ' $71.2 \%$ ', ' $4.6 \%$ ', and ' $1.4 \%$ ', respectively. These ratios should read as ' $73.7 \%$ ', ' $4.0 \%$ ', and ' $1.3 \%$ ', respectively. In addition, the estimated ratio of indels in the coding regions that could cause frameshift mutations is incorrectly written as ' $66.7 \%$ '. It should read as ' $66.9 \%$ '. Furthermore, authors' given names and surnames of Reference 47 are switched. The authors' names should read 'Grassi F., De Mattia F., Zecca G., Sala F., \& Labra M.'. These have been corrected in both the PDF and HTML versions of the Article.

Published online: 06 May 2020

Open Access This article is licensed under a Creative Commons Attribution 4.0 International License, which permits use, sharing, adaptation, distribution and reproduction in any medium or format, as long as you give appropriate credit to the original author(s) and the source, provide a link to the Creative Commons license, and indicate if changes were made. The images or other third party material in this article are included in the article's Creative Commons license, unless indicated otherwise in a credit line to the material. If material is not included in the article's Creative Commons license and your intended use is not permitted by statutory regulation or exceeds the permitted use, you will need to obtain permission directly from the copyright holder. To view a copy of this license, visit http://creativecommons.org/licenses/by/4.0/.

(C) The Author(s) 2020 